\title{
O NOVO ESTATUTO DA PESSOA COM DEFICIÊNCIA E SUAS REPERCUSSÕES NO CASAMENTO E UNIÃO ESTÁVEL ${ }^{1}$
}

\author{
MISUSE ABUSIVE ADVERTISING IN VIRTUAL RELATIONSHIPS: THE RECOGNITION OF \\ CONSUMER VULNERABILITY IN THE CONSUMER MARKET
}

Rafaela Amaral RODRIGUES ${ }^{2}$

Renato Luís MELO FILHO ${ }^{3}$

ISSUE DOI: $10.21207 / 2675-0104.2018 .725$

\begin{abstract}
RESUMO
O objetivo principal deste trabalho é estudar como o novo Estatuto da Pessoa com Deficiência influenciou no Código Civil e Código Processo Civil, principalmente em relação ao casamento e à união estável dos deficientes e suas as principais características, pois tal Estatuto trouxe ampla autonomia e igualdade para as pessoas com deficiência, com o propósito de fazer jus à dignidade da pessoa humana. Portanto, com a plena capacidade para os atos civis, houve a oportunidade de os deficientes constituírem matrimônio e união estável, conforme será tratado nesta pesquisa.
\end{abstract}

\footnotetext{
${ }^{1} \mathrm{O}$ presente artigo sintetiza a monografia de conclusão da pesquisa, realizada para o Programa Interno de Bolsas de Iniciação Científica (PIBIC 2017-2018) da Faculdade de Direito de Franca (FDF), Franca/SP.

${ }^{2}$ Discente da Faculdade de Direito de Franca (FDF), Franca/SP. Bolsista do Programa Interno de Bolsas de Iniciação Científica (PIBIC 2017-2018).

${ }^{3}$ Mestre em Direito Público (Direito Processual Civil-Direito Constitucional) pela UNESP Universidade Estadual Paulista Júlio de Mesquita Filho (2015). Graduado em Direito pela UNESP Universidade Estadual Paulista Júlio de Mesquita Filho (2011). Advogado (desde 2012). Professor Substituto de Direito Processual Civil da UNESP - Universidade Estadual Paulista Júlio de Mesquita Filho (desde 2016). Professor da Faculdade de Ensino São Luís de Jaboticabal (desde 2016). Coordenador (2017) e Professor (desde 2016) da Escola Superior de Advocacia (ESA) - Núcleo Franca, onde ministrou o curso "Aprenda a Trabalhar com o Novo CPC" ( $1^{\circ}$ semestre/2016). Professor Substituto e Colaborador da Faculdade de Direito de Franca (FDF), onde orienta Pesquisas de Iniciação Científica, Trabalhos de Conclusão de Curso (desde 2015)
} 
Palavras-chave: Direito civil. Estatuto da pessoa com deficiência. Casamento. União estável.

\begin{abstract}
The main objective of this study is to study how the new Statute of the Person with Disabilities influenced the Civil Code and the Civil Procedure Code, mainly in relation to marriage and the stable union of the disabled and their main characteristics, since this Statute brought ample autonomy and equality to people with disabilities, in order to live up to the dignity of the human person. Therefore, with full capacity for civil acts, there was the opportunity for the disabled to constitute marriage and stable union, as will be treated in this research.
\end{abstract}

Keyword: Civil Code. Statute of disabled person. Marriage. Stable union.

\title{
INTRODUÇÃO
}

A Constituição Federal de 1988, além de trazer consigo texto normativo com o objetivo de demonstrar o seu objetivo social, trouxe também normas e princípios que demonstram sua tendência para a proteção do indivíduo dentro do ambiente social em que ele se encontra.

Assim, entre os objetivos principais, destaca-se a dignidade da pessoa humana e o princípio da igualdade, resguardados não só na Constituição Federal, como também em tratados e convenções internacionais.

O Brasil foi um dos Estados signatários da Convenção Internacional dos Direitos da Pessoa com Deficiência, homologada em 13 de dezembro de 2006 em Nova Iorque, com o principal objetivo de fornecer aos deficientes ampla autonomia para que eles sejam reconhecidos e respeitados na sociedade em condição de igualdade.

Portanto, como requisito da Convenção de Nova Iorque, o Brasil necessitou elaborar um texto normativo próprio para que aquilo que foi discutido na Convenção pudesse ser positivado na legislação nacional. Dessa forma, foi promulgada a Lei 13.146/2015, também chamada de Estatuto da Pessoa com Deficiência.

Assim sendo, o presente trabalho tem o escopo de esmiuçar o instituto da Lei 13.146/15, em seu sentido mais amplo, a fim de trazer uma ideia geral desta e, para tanto, analisa-se no capítulo primeiro o conceito e a denominação de deficiência, a Convenção Internacional acima citada, como também o novo Estatuto da Pessoa com Deficiência.

No segundo capítulo, realiza-se a inserção da Lei 13.146/15 no ordenamento jurídico brasileiro e sua repercussão na Constituição Federal, por meio dos princípios da dignidade da pessoa humana e da igualdade. Assim como no Código Civil, por meio da alteração do instituto da 
incapacidade e no Código de Processo Civil, a respeito do instituto da curatela.

Posteriormente, no terceiro capítulo, demonstra-se os aspectos gerais do instituto do casamento e da união estável, bem como o funcionamento do matrimônio em relação aos deficientes.

Por fim, para elaboração deste trabalho foi utilizado o método dedutivo, realizando-se pesquisas bibliográficas em doutrinas, livros especializados, artigos e páginas da internet, analisando importantes teorias e legislações aplicadas ao tema.

\section{2 \\ O NOVO ESTATUTO DA PESSOA COM DEFICIÊNCIA}

\section{1}

\section{DENOMINAÇÃO E CONCEITO DE DEFICIÊNCIA}

Conforme é explicado por Carvalho ${ }^{4}$, antigamente eram empregadas expressões como "inválidos", "incapazes", "retardados" e "excepcionais" para se referir a esse grupo, fornecendo, desse modo, sentido discriminatório de inferiorização e exclusão social.

A Constituição Federal de 1988 adotou a expressão "pessoa portadora de deficiência", tendo aplicabilidade nas demais legislações ordinárias. Foram adotados também os termos "pessoas com necessidades especiais" e "pessoa especial" que se espelham em "(...) uma transformação de tratamento, que vai da invalidez e incapacidade à tentativa de nominar a característica peculiar da pessoa, sem estigmatizá$1 \mathrm{a} " 5$

A Convenção da Organização das Nações Unidas sobre os Direitos da Pessoa com Deficiência ${ }^{6}$, que será ainda abordada neste capítulo, adotou em seu bojo a expressão "pessoa com deficiência", principalmente porque sobrepõe o termo "pessoa" antes da deficiência.

\footnotetext{
${ }^{4}$ CARVAlHO, Maria de Lourdes. A Empresa Contemporânea: sua função social em face das pessoas com deficiência. Belo Horizonte: Del Rey, 2012, p. 77.

${ }^{5}$ Ibidem.

${ }^{6}$ BRASIL. Decreto $\mathbf{n}^{0}$ 6.949, de 25 de agosto de 2009. Promulga a Convenção Internacional sobre os Direitos das Pessoas com Deficiência e seu Protocolo Facultativo, assinados em Nova York, em 30 de março de 2007. Diário Oficial da União, 26 de ago. 2009.
} 
Desta maneira, a Convenção da Organização das Nações Unidas sobre os Direitos da Pessoa com Deficiência, no Preâmbulo, alínea "e", trata a respeito da origem do conceito de deficiência:

[...] a deficiência é um conceito em evolução e que a deficiência resulta da interação entre pessoas com deficiência e as barreiras devidas às atitudes e ao ambiente que impedem a plena e efetiva participação dessas pessoas na sociedade em igualdade de oportunidades com as demais pessoas.

O Estatuto da Pessoa com Deficiência ${ }^{7}$, que será analisado posteriormente, no seu artigo $2^{\circ}$, trouxe o seguinte conceito:

Art. $2^{\circ}$ - Considera-se pessoa com deficiência aquela que tem impedimento de longo prazo de natureza física, mental, intelectual ou sensorial, o qual, em interação com uma ou mais barreiras, pode obstruir sua participação plena e efetiva na sociedade em igualdade de condições com as demais pessoas.

\subsection{CONVENÇÃO INTERNACIONAL DA PESSOA COM DEFICIÊNCIA}

A Convenção Internacional sobre os Direitos da Pessoa com Deficiência iniciou com a pretensão de reconhecimento, tutelando, dessa forma, os direitos humanos e liberdades fundamentais em proveito da própria pessoa com deficiência, para que tenha a promoção da igualdade de condições e tratamentos em relação aos demais.

A Convenção da Organização das Nações Unidas sobre os Direitos das Pessoas com Deficiência foi homologada em 13 de dezembro de 2006, mas somente teve início em 3 de maio de 2008, porque obteve mais de vinte alterações. A Convenção Internacional refletiu em aproximadamente 650 milhões de pessoas com deficiência e adotou as especificidades que tornam concretos para o grupo os direitos e as garantias fundamentais estabelecidos pela Declaração Universal dos Direitos Humanos. $^{8}$

\footnotetext{
${ }^{7}$ BRASIL. Lei $\mathbf{n}^{\mathbf{0}}$ 13.146, de 6 de julho de 2015. Institui a Lei Brasileira de Inclusão da Pessoa com Deficiência (Estatuto da Pessoa com Deficiência). Diário Oficial da União, 7 de jul. 2015.

${ }^{8}$ MAIOR, Izabel Maria Madeira de Loureiro. Artigo $4^{\circ}$ - Obrigações Gerais. In: RESENDE, Ana Paula Crosara; VITAL, Flávia Maria de Paiva. A convenção sobre os Direitos da Pessoa com Deficiência Comentada. Brasília: Secretaria Especial dos Direitos Humanos. Coordenadoria Nacional para Integração da Pessoa Portadora de Deficiência, 2008. p. 33-35. Disponível em: $<$ https://www.governoeletronico.gov.br/documentos-e-
} 


\subsection{O ESTATUTO DA PESSOA COM DEFICIÊNCIA}

É de suma importância observar que legislador enalteceu a igualdade de oportunidades e condições, presentes no corpo legal repetidas 24 vezes. Enquanto a palavra "autonomia" foi empregada em 11 repetições. Dessa forma, conclui-se o extremo mérito desses dois componentes no direito da pessoa com deficiência.

Em síntese, salienta-se que o Estatuto da Pessoa com Deficiência tem como objetivo principal efetivar princípios e regras previstos a partir da Convenção Internacional sobre os Direitos da Pessoa com Deficiência. Por conta disso, o Estatuto embarcou novos institutos jurídicos concernentes à concepção de deficiência, capacidade legal e interdição, além das condições de acessibilidade. Portanto, verifica-se que a Lei $n^{\circ} 13.146 / 2015$ traz uma nova política de inclusão, sendo necessária, no entanto, sua implementação de forma consistente, através de políticas públicas, uma vez que apenas sua adoção formal não torna a sociedade mais igualitária e respeitosa dos direitos e garantias fundamentais.

\section{A INFLUÊNCIA DO ESTATUTO NOS DEMAIS RAMOS DO DIREITO}

\subsection{APLICABILIDADE DA IGUALDADE E DIGNIDADE DA PESSOA HUMANA}

A tutela às pessoas com deficiência não está presente em um capítulo próprio no texto constitucional, mas espalhado por toda a Constituição, podendo ser relacionado desde o preâmbulo até Ato das Disposições Constitucionais, condizentes ao deficiente como ser humano 
ou em relação a sua condição específica (artigo 23, II; artigo 24, inciso XIV; artigo $227, \S 2^{\circ}$ e artigo 224 do ADCT). ${ }^{9}$

O princípio da dignidade da pessoa humana pode ser interpretado como a imperatividade do Direito contra todas as maneiras de discriminação humana. Desse modo, se faz necessário que tal princípio possa ser efetivo na sociedade, principalmente através de políticas públicas, a fim de que realmente seja aplicada a convivência harmônica entre aqueles que possuem os mesmos direitos. ${ }^{10}$

Outro princípio que reflete de maneira positiva aos deficientes é da igualdade, fundamentado através do caput do art. $5^{\circ}$ da Constituição Federal:

Art. $5^{\circ}$ Todos são iguais perante a lei, sem distinção de qualquer natureza, garantindo-se aos brasileiros e aos estrangeiros residentes no País a inviolabilidade do direito à vida, à liberdade, à igualdade, à segurança e à propriedade, nos termos seguintes:

Silva ${ }^{11}$ critica que a igualdade não deve ser considerada meramente como princípio, mas sim como valor democrático, no sentido de que a democracia é instrumento para a concretização da igualdade material.

\subsection{ALTERAÇÃO DO INSTITUTO DA INCAPACIDADE}

Antes da elaboração do Estatuto da Pessoa com Deficiência, o ordenamento cível brasileiro estabelecia a incapacidade dos deficientes. Contudo, com a Lei 13.146/15, importante mudança foi introduzida ao retirar este grupo da condição de incapazes, principalmente com a revogação de boa parte dos artigos $3^{\circ}$ e $4^{\circ}$ do Código Civil de 2002. ${ }^{12}$

Apesar da mudança fornecer ampla capacidade para os deficientes mentais, mantem-se a possiblidade de que eles ainda possam

\footnotetext{
${ }^{9}$ BRASIL. Senado Federal. Da Comissão de Direito Humanos e Legislação Participativa, sobre o Projeto de Lei do Senado $\mathrm{n}^{\circ}$ 6, de 2003, de autoria do Senador Paulo Paim, que institui o Estatuto do Portador de Deficiência e dá outras providências. Parecer normativo n ${ }^{\circ} 1.268$ de 13 de dezembro de 2006. Relator: Senador Flávio Arns. p. 3.

${ }^{10}$ SIQUEIRA, Direceu Pereira e AMARAL, Sérgio Tibiriçá. Direitos Humanos: um olhar sob o viés da inclusão social. Birigui: Boreal Editora, 1ª ed., 2012, p. 256-257.

${ }^{11}$ SILVA, José Afonso. Curso de direito constitucional positivo. 22. ed. São Paulo: Malheiros Editores, 2003. p. 126.

${ }^{12}$ REQUIÃO, Maurício. Estatuto da pessoa com deficiência, incapacidades e interdição. Salvador: Juspodivm, 2016, p. 161.
} 
ser submetidos ao instituto da curatela, conforme será abordado no próximo tópico. Dessa forma, o que se afasta é a condição de incapacidade civil dos deficientes.

É possível que o transtorno mental que o deficiente o impossibilite de exprimir sua vontade, transitória ou permanentemente, fato que encaixaria a pessoa como incapaz por força do art. $4^{\circ}$, III. ${ }^{13}$ Contudo, a incapacidade não seria devido ao fato da pessoa ser deficiente, mas sim da impossibilidade de exprimir sua vontade.

A preocupação doutrinária se concentra principalmente na questão prática, "há pessoas que por fatores físicos são incapazes de manifestar sua vontade, mas passam a ser capazes por força da nova lei”. ${ }^{14}$ Com essa afirmação, José Fernando Simão critica que no cotidiano o deficiente não é capaz de manifestar suas vontades, indo ao encontro com o novo dispositivo legal.

Contudo, esse entendimento não se atentou ao que foi definido no art. $4^{\circ}$, III do Código Civil, que mantém a incapacidade das pessoas que não podem manifestar sua vontade, ainda que seja considerada relativa, recebendo a assistência necessária.

Analisando essa linha de raciocínio, é possível constatar que o regime de capacidade adotado anteriormente era fundado principalmente na ideia patrimonialista. Portanto, com o advento da nova Lei que fundamentou a alteração da incapacidade principalmente na garantia da dignidade da pessoa humana e não voltada à tutela patrimonial, houve um choque entre aqueles que mantinham a ideia anterior e os que analisaram a Lei com fulcro no princípio da igualdade.

\subsection{INOVAÇÕES NO INSTITUTO DA CURATELA}

A interdição é caracterizada como o processo que estabelece a curatela da pessoa incapaz. Contudo, tal expressão apresenta uma ideia de limitação do indivíduo a que ela é consolidada, quando, na verdade, o intuito do instituto é atribuir autonomia ao curatelado. ${ }^{15}$

\footnotetext{
${ }^{13}$ CORREIA, Atalá. Estatuto da pessoa com deficiência traz inovações e dúvidas. In: Consultor Jurídico. Disponível em 〈www.conjur.com.br〉. Acesso em 16 mar. 2018.

${ }^{14}$ SIMÃO, José Fernando. Estatuto da Pessoa com Deficiência Causa Perplexidade(Parte I). 2015. Disponível em: <http://www.conjur.com.br/2015-ago-07/jose-simao-estatuto-pessoa-deficiencia-trazmudancas\#author>. Acesso em: 02 jul. 2018.

${ }^{15}$ REQUIÃO, Maurício. Estatuto da pessoa com deficiência, incapacidades e interdição. Salvador: Juspodivm. 2016. p. 170.
} 
Para a propositura da ação de curatela, o novo Código de Processo Civil, por meio do art. 747, estabelece que a legitimidade ativa cabe, desde que comprovada a qualificação do requerente, ao cônjuge ou companheiro, parente ou afins, representante da entidade em que se encontra abrigado o interditando e pelo Ministério Público. ${ }^{16}$

Compete ao requerente da interdição comprovar, conforme expresso no art. 749 do NCPC, não somente os fatos que justificam a propositura da ação, como também o momento em que a incapacidade se evidenciou. Quando esta demonstração for impossível de ser demonstrada, tal deverá ser justificada na petição inicial. ${ }^{17}$

O levantamento da curatela acontecerá quando cessar o motivo que a ocasionou. $\mathrm{O}$ pedido de levantamento poderá ser formulado pelo interdito, pelo curador ou pelo Ministério Público, que será apensado aos autos do processo da interdição. ${ }^{18}$

4

\section{O CASAMENTO E A UNIÃO ESTÁVEL DA PESSOA COM DEFICIÊNCIA}

\subsection{O PRINCÍPIO DA AFETIVIDADE NAS RELAÇÕES MATRIMONIAIS}

A Carta Magna de 1988 trouxe, através do Capítulo VII, do Título VIII, um capítulo próprio para tratar a respeito da família, da criança, do adolescente, do jovem e do idoso. Conforme interpretação do art. 226, pode-se dizer que a família é decorrente do casamento civil, garantindo a celebração gratuita e tendo efeito civil o casamento religioso; a união estável entre homem e mulher, devendo a lei facilitar a conversão em matrimônio e a família monoparental, formada por qualquer dos pais e seus descendentes. ${ }^{19}$

Tem prevalecido, na doutrina e na jurisprudência, principalmente no STF e STJ, o entendimento de que o rol trazido pela Constituição é

\footnotetext{
${ }^{16}$ Idem. p. 171.

${ }^{17}$ Idem, p. 173.

${ }^{18}$ Idem, 181.

${ }^{19}$ TARTUCE, Flávio. Manual de Direito Civil. 8. ed. São Paulo: Método, 2018. p. 1338.
} 
exemplificativo e não taxativo, porque abrange também as categorias de família anaparental, família homoafetiva ou família pluriparental. ${ }^{20}$

A legislação brasileira não trouxe um conceito expresso de casamento, desse modo, por possuir entendimento amplo, não é possível determinar precisamente definir este instituto. Analisando os conceitos doutrinários, Maria Helena Diniz ${ }^{21}$ conceitua como "É o casamento a mais importante e poderosa de todas as instituições de direito privado, por ser uma das bases da família, que é a pedra angular da sociedade".

Após a parte introdutória a respeito do princípio da afetividade e do casamento, o próximo tópico irá tratar especificamente do casamento da pessoa com deficiência após a vigência da Lei 13.146/15.

\subsection{A REPERCUSSÃO DA LEI 13.146/15 NO CASAMENTO}

Como não há regras expressas no ordenamento jurídico a respeito da capacidade para o casamento, os operadores do direito se recorrem à Parte Geral do Código Civil, em complemento ao que consta no art. 1.517. Contudo, conforme analisado no capítulo anterior, a Lei 13.146/15 alterou substancialmente a teoria da incapacidade. ${ }^{22}$

Dessa forma, com as alterações citadas, o sistema encontrou uma harmonia técnica, pois, conforme o art. 1.517, apenas os menores de 16 anos são incapazes para o casamento, estando em consonância com o art. $3^{\text {o }}$ do Código Civil, atualizado com a Lei 13.146/15.

Conforme se observa, o Estatuto pretendeu alcançar a igualdade para os deficientes para os atos existenciais, representando um notável avanço ao direito. Portanto, na proteção a este grupo, substituiu-se a premissa da dignidade-vulnerabilidade pela dignidade-igualdade.

Outra alteração do Código Civil, decorrente da Lei 13.146/15, foi em relação à anulabilidade do casamento. $\mathrm{O}$ art. 1.557 , inciso III considera anulável o casamento celebrado havendo erro essencial quanto à pessoa do outro cônjuge, contudo, que não caracterize deficiência. Além disso, o inciso IV foi totalmente revogado, que considerava anulável o casamento quanto "a ignorância, anterior ao casamento, de doença mental grave que,

\footnotetext{
${ }^{20}$ TARTUCE, Flávio. Manual de Direito Civil. 8. ed. São Paulo: Método, 2018. p. 1338.

${ }^{21}$ DINIZ, Maria Helena. Curso de Direito Civil Brasileiro: Direito de Família. 22. ed. São Paulo: Saraiva, 2007. p. 35.

${ }^{22}$ TARTUCE, Flávio. Manual de Direito Civil. 8. ed. São Paulo: Método, 2018. p. 1343.
} 
por sua natureza, torne insuportável a vida em comum ao cônjuge enganado".

As reformas dos artigos relativos ao direito de família, conforme analisadas, tiveram o propósito principal de garantir a dignidade humana da pessoa com deficiência.

3.3 Possibilidade do deficiente em constituir união estável

Partindo do que estabelece a Constituição Federal, a união estável é reconhecida entre o homem e a mulher como entidade familiar, prevendo que a lei deve facilitar sua conversão em casamento. ${ }^{23}$

Duas conclusões podem ser interpretadas de acordo com a Carta Magna, primeiramente é a diferenciação com o casamento, dado que categorias opostas não podem ser convertidas uma na outra e também é que não há hierarquia entre casamento e união estável. ${ }^{24}$

Portanto, quanto às pessoas com deficiência, não é possível constatar impedimentos para que este grupo possa constituir união estável. Porque, após a vigência da Lei 13.146/2015, através do art. $6^{\circ}$, conforme analisado no tópico anterior, as pessoas com deficiência são livres para casar e constituir união estável. ${ }^{25}$

No entanto, esse instituto não poderá ser reconhecido caso houver algum dos impedimentos previstos no Art. 1521 do CC/02, que de forma análoga, elenca um rol daqueles que não podem constituir matrimônio.

No entanto, esse instituto não poderá ser reconhecido caso houver algum dos impedimentos previstos no Art. 1521 do CC/02, que de forma análoga, elenca um rol daqueles que não podem constituir matrimônio.

Contudo, caso o deficiente não preencha algum requisito dos incisos do artigo supracitado e estando presente a estabilidade, continuidade e publicidade, além da manifesta vontade de constituir família, compõem os elementos essenciais a união estável. Esta poderá ser reconhecida mesmo não apresentando prazo, independentemente se os relacionados são deficientes ou não, pois a norma não os distinguiu em relação às demais pessoas, prosperando, assim, um tratamento igualitário. ${ }^{26}$

\footnotetext{
${ }^{23}$ TARTUCE, Flávio. Manual de Direito Civil. 8. ed. São Paulo: Método, 2018. p. 1483.

${ }^{24}$ LÔBO, Paulo. Famílias. São Paulo: Saraiva, 2008, p. 151.

${ }^{25}$ FARIAS, Cristiano Chaves; CUNHA, Rogério Sanches; PINTO, Ronaldo Batista. Estatuto da Pessoa com Deficiência Comentado artigo por artigo. Salvador: Juspodivm, 2016. p. 43.

${ }^{26}$ Ibidem.
} 


\section{REFERÊNCIAS BIBLIOGRÁFICAS}

BRASIL. Decreto ${ }^{\circ}$ 6.949, de 25 de agosto de 2009. Promulga a Convenção Internacional sobre os Direitos das Pessoas com Deficiência e seu Protocolo Facultativo, assinados em Nova York, em 30 de março de 2007. Diário Oficial da União, 26 de ago. 2009.

BRASIL. Lei no 13.146, de 6 de julho de 2015. Institui a Lei Brasileira de Inclusão da Pessoa com Deficiência (Estatuto da Pessoa com Deficiência). Diário Oficial da União, 7 de jul. 2015.

BRASIL. Senado Federal. Da Comissão de Direito Humanos e Legislação Participativa, sobre o Projeto de Lei do Senado $\mathrm{n}^{\circ}$ 6, de 2003, de autoria do Senador Paulo Paim, que institui o Estatuto do Portador de Deficiência e dá outras providências. Parecer normativo $\mathrm{n}^{\circ} 1.268$ de 13 de dezembro de 2006. Relator: Senador Flávio Arns.

CARVALHO, Maria de Lourdes. A Empresa Contemporânea: sua função social em face das pessoas com deficiência. Belo Horizonte: Del Rey, 2012.

CORREIA, Atalá. Estatuto da pessoa com deficiência traz inovações e dúvidas. In: Consultor Jurídico. Disponível em <www.conjur.com.br〉. Acesso em 16 mar. 2018.

LÔBO, Paulo. Famílias. São Paulo: Saraiva, 2008.

MAIOR, Izabel Maria Madeira de Loureiro. Artigo $4^{\circ}$ - Obrigações Gerais. In: RESENDE, Ana Paula Crosara; VITAL, Flávia Maria de Paiva. A convenção sobre os Direitos da Pessoa com Deficiência Comentada. Brasília: Secretaria Especial dos Direitos Humanos. Coordenadoria Nacional para Integração da Pessoa Portadora de Deficiência, 2008. p. 33-35. Disponível em:

$<$ https://www.governoeletronico.gov.br/documentos-e arquivos/A\%20Convencao\%20sobre $\% 20$ os $\% 20$ Direitos \%

20das\%20Pessoas\%20com\%20Deficiencia\%20Comentada.pdf> Acesso em: 5 out. 2017.

REQUIÃO, Maurício. Estatuto da pessoa com deficiência, incapacidades e interdição. Salvador: Juspodivm, 2016.

SILVA, José Afonso. Curso de direito constitucional positivo. 22. ed. São Paulo: Malheiros Editores, 2003.

SIMÃO, José Fernando. Estatuto da Pessoa com Deficiência Causa Perplexidade(Parte I). 2015. Disponível em: <http://www.conjur.com.br/2015-ago-07/jose-simao-estatuto-pessoa-deficiencia-trazmudancas\#author>. Acesso em: 02 jul. 2018.

SIQUEIRA, Direceu Pereira e AMARAL, Sérgio Tibiriçá. Direitos Humanos: um olhar sob o viés da inclusão social. Birigui: Boreal Editora, $1^{\text {a }}$ ed., 2012

TARTUCE, Flávio. Manual de Direito Civil. 8. ed. São Paulo: Método, 2018. 